\title{
Happy@Work
}

\section{Effectiveness of a preventive web-based guided self-help course for employees with depressive symptoms}

Anna Geraedts, ${ }^{12}$ Annet Kleiboer, ${ }^{12}$ Noortje Wiezer, ${ }^{2}{ }^{3}$ Willem van Mechelen, ${ }^{2} 4$ Pim Cuijpers, ${ }^{12}$

${ }^{1}$ Department of Clinical Psychology \& EMGO Institute for Health and Care Research, VU University \& VU University Medical Center Amsterdam, The Netherlands,
${ }^{2}$ Body@Work, Research Center on Physical Activity, Work and Health, TNO-VU University Medical Centre, Amsterdam, The Netherlands,

${ }^{3}$ TNO, Work, Health and Care, Hoofddorp, The Netherlands, ${ }^{4}$ Institute for Research in Extramural Medicine, Department of Social Medicine, VU University Medical Center, Amsterdam, The Netherlands

\section{Aim}

The goal of this project is to test the effectiveness of a preventive web-based guided self-help course for employees with depressive symptoms.

\section{Background}

Depressive disorders are highly prevalent in the working population and are associated with excessive costs for both society and companies. Prevention of depression is in the interest of companies because they pay about $75 \%$ of the total economic costs of depression. These costs include absenteeism and loss of work productivity (presenteeism). Hence, we developed a web-based guided self-help course for employees with depressive symptoms (Happy@Work).

\section{Happy@Work}

The intervention Happy@Work is a brief web-based self-help course with guidance from a coach. Happy@Work is based on Problem Solving Treatment, Cognitive Therapy and a guideline to help employees with work related stress problems. It consists of 6 weekly lessons that involve information and assignments. The assignments are provided with feedback from a coach via the website.

Geraedts, A. S., Kleiboer, A. M., Wiezer, N. M., van Mechelen, W., \& Cuijpers, P. Webbased guided self-help for employees with depressive symptoms (Happy@Work): design of a randomized controlled trial. BMC Psychiatry, 2013, 13:61.

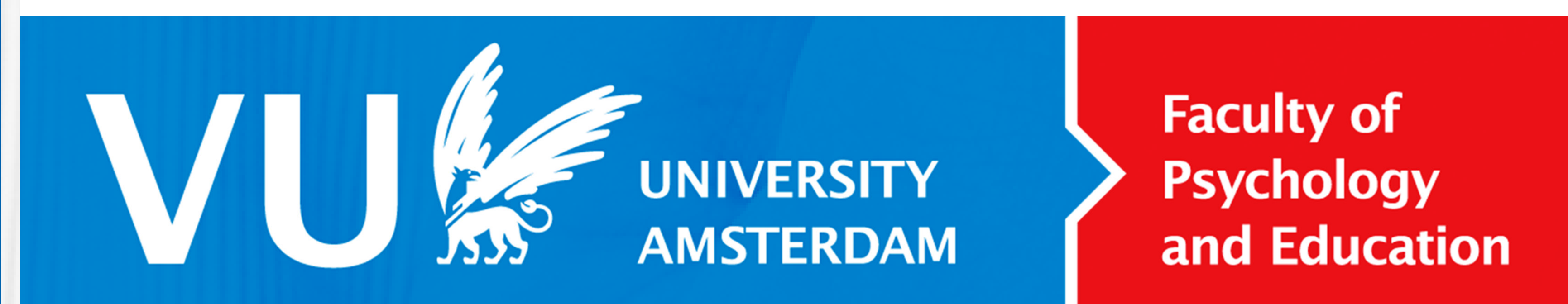

\section{Methods}

The study is a two arm randomized controlled trial comparing Happy@Work with care-as-usual (CAU). Employees with depressive symptoms who were not on sick leave were eligible for taking part in this study.

Data from online questionnaires were collected at baseline and 8 weeks after baseline (post treatment). The primary outcome was depressive symptoms (CES-D). Secondary outcomes were anxiety (HADS), burnout symptoms (MBI-GS), and work performance (WHO HPQ).We also collected data on the evaluation of Happy@Work. Data were analyzed on the intention-to-treat (ITT) principle, missing data were handled with use of Multiple Imputation (MI) in SPSS.

\section{Results}

A total of 231 employees were recruited in six different (international) companies in the Netherlands, $95 \%$ were white collar workers. There were no significant differences between the groups at baseline with respect to demographics and symptoms (Table $1 \& 2$ ).

Evaluations of Happy@Work were positive. On a 1-10 scale, the website scored 7.4, the course scored 7.4, and the feedback scored 7.7 .

Of the 231 employees, $172(74.5 \%)$ completed the post-treatment questionnaires. No significant differences between the intervention group and the control group were found on depressive symptoms (effect size .18), anxiety, burnout symptoms or work performance (Table 2).

More information and contact: www.bodyatwork.nl Email Anna Geraedts: a.s.geraedts@vu.nl
Table 1. Baseline characteristics of the participants

\begin{tabular}{ccccc} 
Characteristic & $\begin{array}{c}\text { All (N=231) } \\
\text { No. (\%) }\end{array}$ & $\begin{array}{c}\text { Intervention } \\
(\mathrm{N}=116) \\
\text { No. (\%) }\end{array}$ & $\begin{array}{c}\text { Control } \\
(\mathrm{N}=115) \\
\text { No. }(\%)\end{array}$ & P-value \\
\hline $\begin{array}{c}\text { Gender } \\
\text { Female }\end{array}$ & $144(62.3)$ & $77(66.4)$ & $67(58.3)$ & .20 \\
Age (mean, SD) & $43.0(9.3)$ & $42.6(8.9)$ & $43.3(9.6)$ & .59 \\
$\begin{array}{c}\text { Education } \\
\text { High }\end{array}$ & $147(63.6)$ & $74(63.8)$ & $73(63.5)$ & .96 \\
$\begin{array}{c}\text { Working hours } \\
\text { Week (mean, SD) }\end{array}$ & $33.9(5.0)$ & $33.7(4.8)$ & $34.0(5.3)$ & .65 \\
\hline
\end{tabular}

Table 2. Effects of Happy@Work on different outcomes

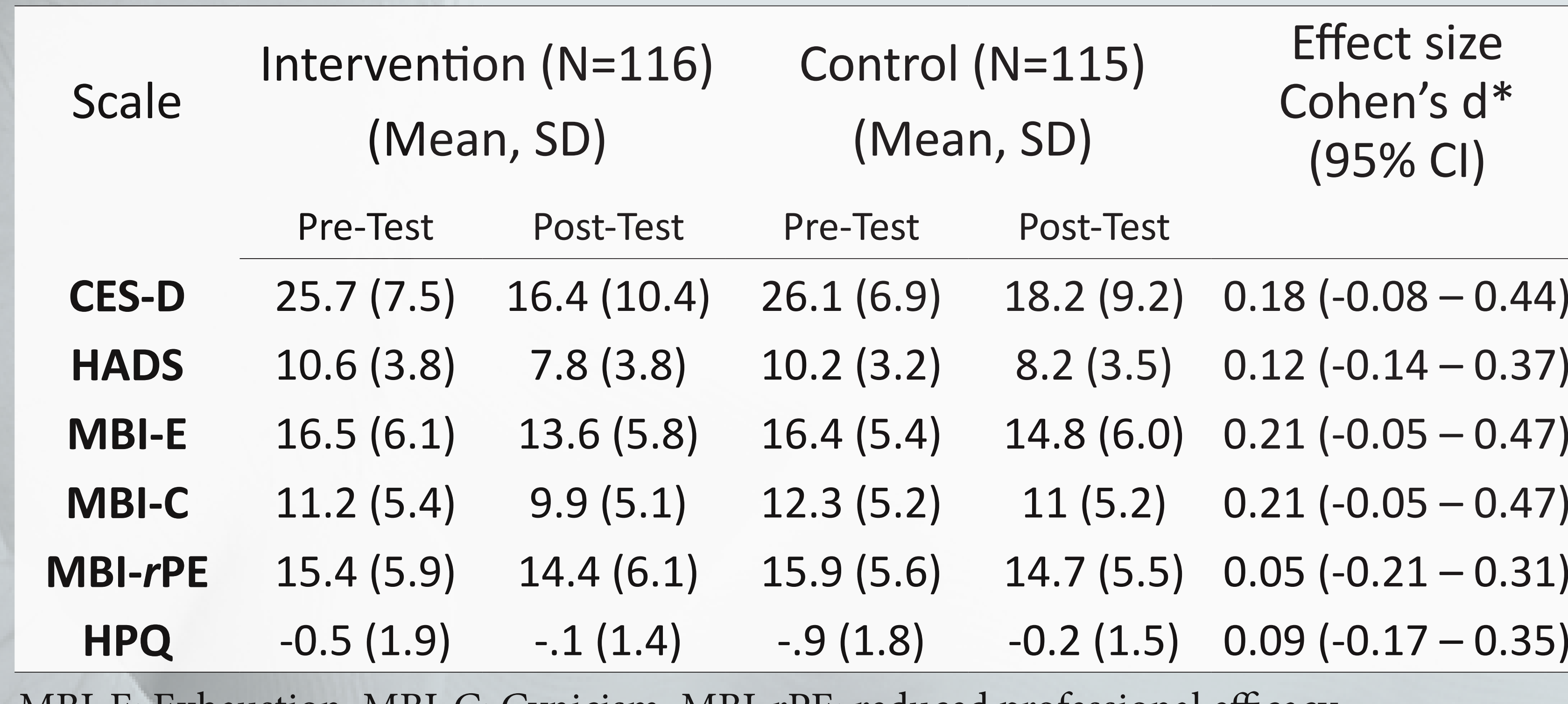
MBI-E: Exhaustion, MBI-C: Cynicism, MBI-rPE: reduced professional efficacy ${ }^{*}$ Cohen's d: $\left(\mathrm{M}_{\mathrm{c}}-\mathrm{M}_{\mathrm{i}}\right) / \mathrm{SD}_{\mathrm{ic}}$

\section{Discussion}

Happy@Work was evaluated positively. However, participants in the intervention group did not show better improvements than the CAU group in terms of depression, anxiety, burnout and work performance. Further analyses may provide insight into the large improvements in the control group (e.g. did they receive any treatment?). Additionally, we will examine the long term effects of Happy@Work at 6 months and 12 months follow-up and we will research its effects on absenteeism, presenteeism, and we will perform a cost-effectiveness analysis. 